\title{
Interdigestive biliary output in man: relationship to fluctuations in plasma motilin and effect of atropine*
}

\author{
T SVENBERG, $\uparrow \mathrm{N}$ D CHRISTOFIDES, M L FITZPATRICK, \\ F AREOLA-ORTIZ, S R BLOOM, and R B WELBOURN
}

From the Departments of Surgery, Medicine and Medical Physics, Royal Postgraduate Medical School, London

SUMmARY The fasting output of bile into the bowel was investigated in nine healthy volunteers by hepatobiliary scanning. Subjects were studied twice, on each occasion for $2 \cdot 5$ hours. A significant flow of radioactivity from the gall bladder to the duodenum was observed on one or two occasions during each experiment. A $32 \pm 4 \%$ mean decrease in counts over the gall bladder was recorded, indicating partial emptying of this organ in the interdigestive state. The output of bile into the bowel was found to be related to fluctuations in fasting plasma motilin levels in that a significant motilin increment $(18 \pm 4 \mathrm{pmol} / \mathrm{l}, \mathrm{p}<0.005)$ paralleled the appearance of radioactivity in the duodenum. The onset of gall-bladder emptying regularly preceded the peak in plasma motilin (mean: $25 \pm 2$ minutes). Atropine, intravenously, $0.6 \mathrm{mg}$ followed by $0.3 \mathrm{mg}$, nearly abolished both fasting biliary output and plasma motilin fluctuations. Thus, bile output appears to occur frequently in fasting humans, but our data do not allow any conclusions as to the possible causal relationship between fasting gall-bladder emptying and release of motilin. Cholinergic influences appear to be of importance in the regulation of interdigestive biliary output in man.

Contraction of the gall bladder and output of bile into the bowel are conventionally considered to occur only after a fatty meal and are presumed to be dependent upon the release of cholecystokinin from the duodenal mucosa. ${ }^{12}$ Recent studies, however, have shown that the biliary tract also exhibits motor activity in the fasting state. Thus, periodic contractions of the canine gall bladder ${ }^{3}$ and cyclic output of bile acids into the bowel of $\operatorname{man}^{4}$ have been observed in relation to the interdigestive myoelectric complex in the proximal gut.

Several reports have suggested that motilin, a recently isolated peptide, might regulate interdigestive gastrointestinal motility. ${ }^{5-7}$ In support of this view it has been found that plasma motilin exhibits cyclic variations in the fasting state, the peak concentration coinciding with the onset of the activity front of the interdigestive myoelectric complex in the stomach or duodenum. ${ }^{89}$ Further-

\footnotetext{
* Presented in part at the BSG Meeting in Exeter. September 1981, and published in abstract form in Gut.

† Address for correspondence: T Svenberg. Department of Surgery. Karolinska Hospital, S-104 01 Stockholm, Sweden.

Received for publication 26 March 1982
}

more, infusion of pure porcine or synthetic motilin causes an increase in gall-bladder pressure in the $\operatorname{dog}^{3}$ and in the pig, ${ }^{10}$ implying a regulatory role of this peptide in biliary tract motility in these animals.

The present investigation was performed in order: (1) to study human interdigestive biliary tract motility with a non-invasive technique and (2) to relate these events to plasma motilin fluctuations, with the aim of evaluating whether or not motilin induces fasting biliary output in man.

\section{Methods}

\section{SUBJECTS}

Biliary tract dynamics were investigated in human subjects by means of hepatobiliary scanning using ${ }^{99} \mathrm{Tc}^{\mathrm{m}}$-EHIDA. ${ }^{11}$

Nine healthy volunteers, five men and four women, aged 24 to 32 years, were studied. Before the experiment they were subjected to a thorough clinical and biochemical investigation. None had a past history of gastrointestinal or hepatobiliary disease. No one admitted to heavy alcohol consumption or was taking any medication or contraceptive steroids. The subjects gave informed 
consent for the study, which was approved by the Research Ethics Committee of the Royal Postgraduate Medical School and the North Hammersmith District Management Team.

The gamma ray emission was detected by a Nuclear Enterprises Mark IV gamma camera with a parallel hole low energy collimator, linked to a Hewlett Packard 2100 A computer. The data were recorded continuously throughout the study and stored on magnetic tape for subsequent analysis. Data were analysed in either 60 second (liver parenchyma) or 120 second intervals. Regions for analysis were chosen over the gall bladder, part of the peripheral liver parenchyma, and that part of the duodenum where activity was first seen after bile had left the biliary tree. The latter area was always located medially and caudally to the liver and was easily distinguished from the hepatobiliary system. Decay-corrected time activity curves were generated for the various regions by the computer. To avoid possible bias these analyses were performed blind.

With the subject in the supine position, the gamma camera was tilted $25^{\circ}$ to the subject's left and $10^{\circ}$ caudally and centred over the gall bladder. This camera position enabled a distinction to be made between the gall bladder and the common bile duct. The camera field was large enough to reveal possible duodenogastric reflux. At the start of each experiment a cannula was inserted into an antecubital vein, the subject rested for 30 minutes under the camera and 25 to $75 \mu \mathrm{Ci}{ }^{99} \mathrm{Tc}^{\mathrm{m}}$-EHIDA were then injected intravenously. Blood $(5 \mathrm{ml})$ was drawn every 10 minutes during the period of observation that is, the 30 minute rest period plus the 2.5 hours after the isotope injection. Blood was centrifuged immediately in heparinised tubes and the plasma samples were frozen on dry ice and stored at $-20^{\circ} \mathrm{C}$ until assayed for motilin. The motilin radioimmunoassay, in which an antiserum (M1) directed against the N-terminal part of motilin was used, ${ }^{12}$ could detect changes of $3 \mathrm{pmol} / \mathrm{l}$ with $95 \%$ confidence. It was performed blind.

Fasting biliary output was assessed twice in each subject, with at least one week between each pair of experiments. The effect of cholinergic blockade on fasting biliary output and motilin release was determined in an additional session on seven of the subjects, four men and three women. Atropine, $0 \cdot 6$ $\mathrm{mg}$, was given intravenously 10 minutes before the isotope injection and, 90 minutes later, a further 0.3 $\mathrm{mg}$ atropine was administered. The subjects in this group were studied for two hours after the ${ }^{99} \mathrm{Tc}^{\mathrm{m}}$ EHIDA injection.

The results were expressed as means \pm SEM. When appropriate, Student's $t$ test for paired data was used for comparison.

\section{Results}

The pattern of hepatobiliary excretion of ${ }^{99} \mathrm{Tc}^{\mathrm{m}}$ EHIDA showed considerable variation except after atropine (see below). The only relatively constant features were the uptake and clearance by the liver (Fig. 1). Maximal activity in the liver parenchyma was recorded after $10 \pm 1$ minutes and $50 \%$ of this activity was cleared by the liver $34 \pm 1$ minutes after the isotope injection.

Time/activity curves over the gall bladder varied between and within subjects. A decrease of at least $10 \%$ in counts over the area of the gall bladder was taken to indicate partial discharge of its content. This event, defined as 'gall-bladder emptying', was always associated with an increase in duodenal activity of at least $100 \%$. Gall-bladder emptying was observed in all studies: once in nine studies and twice in the remaining nine (Table 1). Maximal gall-bladder activity was observed after $54 \pm 5$ minutes. Thereafter, a steady state in gall-bladder counts was seen in only three studies, lasting 20,36 , and 50 minutes respectively, and was followed by gall-bladder emptying. In the remaining 15 experiments the peak activity in the gall bladder was followed immediately by a decrease in counts of

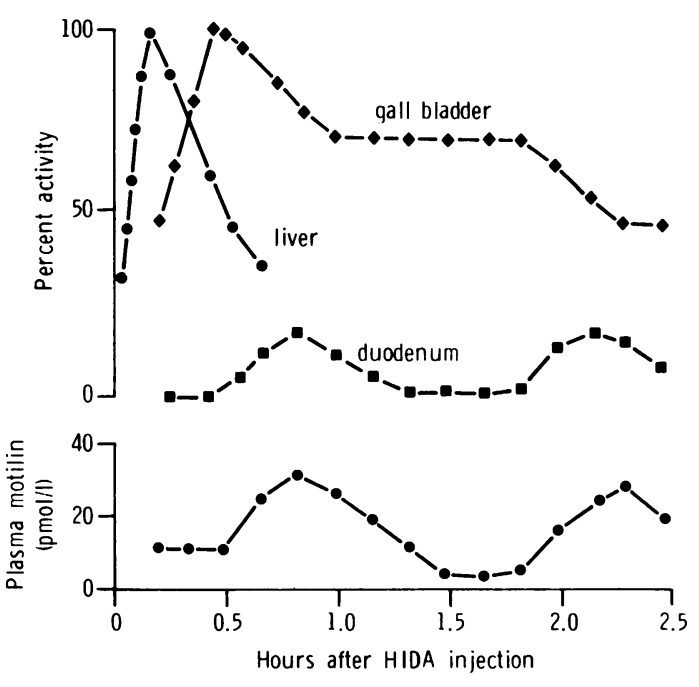

Fig. 1 Timelactivity curves over the liver, the gall bladder and the duodenum after intravenous ${ }^{99} \mathrm{Tc}^{m}$-EHIDA in one fasting subject. Radioactivity decreased twice in the gallbladder area and increased simultaneously in the duodenal area. These events were associated with an increase in plasma motilin concentration. Both the liver and the gall-bladder curves have been normalised to show the maximum activity as $100 \%$. Duodenal activity is expressed as a percentage of maximal gall-bladder activity. 
Table 1 Gall-bladder emptying in nine subjects

\begin{tabular}{|c|c|c|c|c|c|c|c|c|c|}
\hline & \multicolumn{9}{|c|}{ Subject } \\
\hline & 1 & 2 & 3 & 4 & 5 & 6 & 7 & 8 & 9 \\
\hline A & $\begin{array}{l}32 \\
40\end{array}$ & $\begin{array}{l}33 \\
50\end{array}$ & 50 & 20 & $\begin{array}{l}62 \\
19\end{array}$ & $\begin{array}{l}10 \\
15\end{array}$ & $\begin{array}{l}10 \\
30\end{array}$ & $\begin{array}{l}50 \\
70\end{array}$ & 55 \\
\hline B & 12 & $\begin{array}{l}10 \\
14\end{array}$ & 18 & 29 & $\begin{array}{l}38 \\
12\end{array}$ & $\begin{array}{l}12 \\
10\end{array}$ & 20 & 70 & 65 \\
\hline Mean & 28 & 27 & 34 & 25 & 33 & 12 & 20 & 63 & 60 \\
\hline $\mathrm{C}$ & 0 & 0 & - & - & 10 & 0 & 0 & 36 & 0 \\
\hline
\end{tabular}

All figures represent the decrease in gall-bladder activity observed in the gall-bladder area during episodes of emptying, expressed as a percentage of the pre-emptying value. Two experiments (A and B) were performed on each subject without cholinergic blockade and one or two episodes were observed in each experiment (mean decrease $=32 \pm 4 \%$ ). Seven of the subjects were studied after atropine $(\mathrm{C})$ and single episodes of slight gall-bladder emptying were observed in two (mean decrease $=7 \pm 5 \%) .(-=$ not determined.)

\section{$31 \pm 5 \%$.}

After gall-bladder emptying, which took between 10 to 50 minutes $(26 \pm 3)$, a steady state of varying length, 20 to 90 minutes $(46 \pm 5)$, was observed. This lasted until the end of the experiment ( 2.5 hours) in nine instances, or was followed within this period by a second episode of gall-bladder emptying of $28 \pm 5 \%$ in seven studies. In the remaining two, gall-bladder emptying of 32 and $12 \%$ respectively was observed before the maximal gall-bladder activity was reached. The time interval between the onset of the first and second episodes of gall-bladder emptying in these nine studies was $81 \pm 8$ minutes.

There was a striking association between gallbladder emptying and fluctuations in the fasting plasma motilin level (Fig. 1, Table 2). All observed instances of gall-bladder emptying were associated with an increase in plasma motilin. Furthermore, a rise in motilin was never seen without concomitant gall-bladder emptying. In order to elucidate the relationship in time between fluctuations in plasma motilin and the observed onset of gall-bladder emptying, plasma motilin was measured at 10 minute intervals throughout the experiment (Table 2). A rise was always found in the first sample taken after the onset of emptying and the peak level was observed after $25 \pm 2$ minutes. Increments and decrements in plasma motilin relative to the value at the time of onset of gall-bladder emptying were also calculated (Table 2 ) and are summarised in Fig. 2. A small $(3 \pm 1 \mathrm{pmol} / \mathrm{l})$ but significant $(\mathrm{p}<0.01)$ increment was found before the onset of emptying and much larger increase $(18 \pm 4 \mathrm{pmol} / \mathrm{l})$ was observed afterwards.

After the administration of atropine, the pattern
Table 2 Increments and decrements in plasma motilin at 10 minute intervals before and after onset of interdigestive gall-bladder emptying (time 0) observed during a total of 18 studies in nine subjects

\begin{tabular}{rrllllllll}
\hline \multicolumn{1}{l}{ Subject } \\
\cline { 2 - 9 } Time & 1 & 2 & 3 & 4 & 5 & 6 & 7 & 8 & 9 \\
$($ min) & $n=3$ & $n=4$ & $n=2$ & $n=2$ & $n=4$ & $n=4$ & $n=3$ & $n=3$ & $n=2$ \\
\hline-40 & -8 & -1 & +1 & 0 & +7 & +1 & +9 & +13 & 0 \\
-30 & -13 & -1 & -1 & -2 & +3 & -1 & +8 & +7 & -5 \\
-20 & -13 & +1 & +1 & -2 & -4 & +1 & +1 & +3 & -10 \\
-10 & -5 & -3 & -3 & +2 & -7 & -1 & -3 & -3 & -4 \\
0 & 0 & 0 & 0 & 0 & 0 & 0 & 0 & 0 & 0 \\
+10 & 5 & 13 & 12 & 3 & 10 & 9 & 8 & 8 & 16 \\
+20 & 7 & 22 & 25 & 9 & 23 & 11 & 14 & 8 & 44 \\
+30 & 8 & 21 & 25 & 8 & 29 & 9 & 16 & 5 & 46 \\
+40 & 11 & 15 & 28 & 3 & 31 & 5 & 14 & 7 & 41 \\
\hline
\end{tabular}

$n$ depicts the number of gall-bladder emptying episodes observed in each subject. Values are given in $\mathrm{pmol} / \mathrm{l}$ and expressed as mean motilin concentration at time $\times$ minus mean motilin concentration at time 0 .

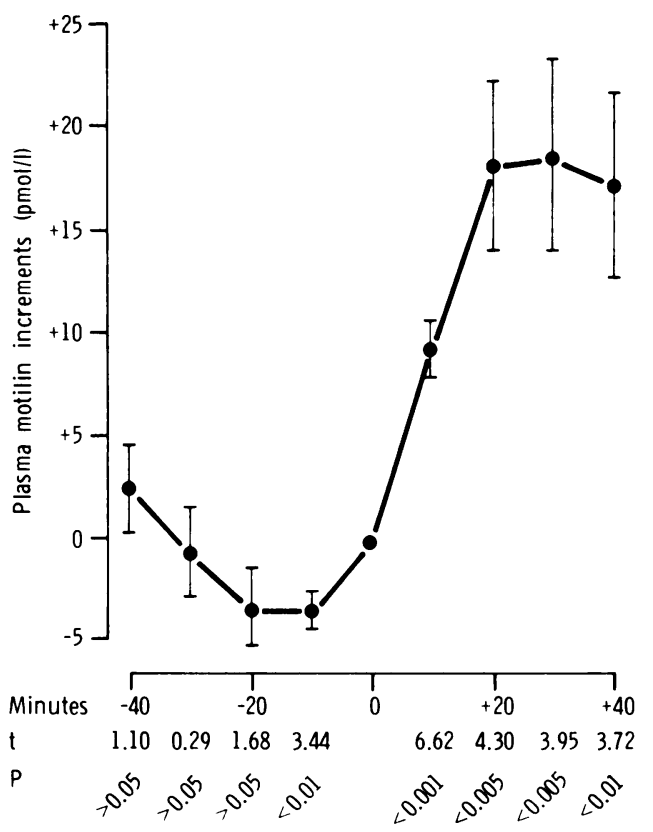

Fig. 2 Motilin increments (ordinate) at different 10 minute intervals (abscissa) before and after the onset of gall-bladder emptying (time 0) in nine subjects. Each point represents the mean $\pm S E M$ of the mean values for each subject (Table 2). Statistical analyses of the differences in motilin concentration between each point and time 0 are shown at the bottom. 
of hepatobiliary ${ }^{99} \mathrm{Tc}^{\mathrm{m}}$-EHIDA excretion was markedly different from that described above, though uptake and clearance by the liver were not significantly changed. In five of the seven subjects, peak activity in the gall bladder was followed by a steady state - that is, less than $5 \%$ variation - which lasted until the end of the experiment. Furthermore, no duodenal activity was found in these subjects. In the remaining two subjects reduced gall-bladder emptying was seen (Table 1), associated with appearance of activity in the bowel. These two subjects also showed an increase in plasma motilin (from 41 to 105 and 4 to $12 \mathrm{pmol} / 1$ respectively) after the onset of gall-bladder emptying. In the other five subjects, fasting plasma motilin fluctuations were abolished by atropine.

No duodenogastric reflux of activity was observed in any of the experiments.

\section{Discussion}

These data show that bile often enters the bowel in the interdigestive state in man, thus confirming the results of Peeters and co-workers, who used a different method to assess biliary dynamics. ${ }^{4}$ They studied normal subjects and patients who had undergone cholecystectomy and found that the pattern of fasting biliary flow into the duodenum was not greatly different in the two groups. This finding suggested that the gall bladder was not required for fasting biliary output in man. The present study, however, suggests that, when present, the gall bladder takes an active part in the interdigestive output of bile, as it was always observed to empty partially when radioactivity appeared in the bowel. It is therefore postulated that the human gall bladder, like its canine counterpart, ${ }^{3}$ exhibits periodic contractions in the fasting state.

Fasting biliary output appears to be dependent on cholinergic influence, as atropine abolished both gall-bladder emptying and flow of bile into the bowel in five subjects and reduced gall-bladder emptying in two.

All subjects showed cyclic variations in their fasting plasma motilin concentrations. This is in accordance with previous investigations, ${ }^{7-9}$ where the plasma motilin peak was shown to coincide with the onset of phase III of the interdigestive myoelectric complex in the upper gut. Furthermore, atropine abolished interdigestive fluctuations in plasma motilin in all but two subjects, in whom much reduced but still significant emptying was seen.

The present data reveal, for the first time, an association between fasting biliary output and plasma motilin fluctuations. Our results do not allow any conclusions as to the possible causal relationship between these events. The finding that onset of gall-bladder emptying always precedes the plasma motilin peak ( $25 \pm 2$ minutes) would seem to favour the view that bile in the duodenum causes motilin release. ${ }^{13}$ The small though significant motilin increment found before the onset of gall-bladder emptying may, however, suggest that motilin actually causes gall-bladder contraction. A further possibility is that a third, unknown factor causes both gall-bladder emptying and motilin release. The effects of atropine on these events may imply that cholinergic reflexes are involved. Our data suggest that fasting gall-bladder emptying is part of the interdigestive myoelectric complex in the upper gut.

Hepatobiliary scanning has been suggested as a suitable method for studying the effects of peptide hormone infusions on the biliary tract. ${ }^{14} 15$ Our data indicate that in such studies the interdigestive gall-bladder contractions must be considered carefully. Pharmacological control of these might be an advantage and it remains to be seen whether this can be achieved by means other than non-selective cholinergic blockade.

The work was supported by a grant from the Wellcome Trust. T Svenberg was the Swedish holder of the Wellcome Swedish Travelling Research Fellowship for 1980-81. The figures were prepared in the Department of Medical Illustrations, Royal Postgraduate Medical School.

\section{References}

1 Guyton AC. In: Textbook of medical physiology. Philadelphia: Saunders, 1976: 863.

2 Sherlock S. In: Diseases of the liver and biliary system. Oxford: Blackwell, 1981: 67.

3 Itoh Z, Takahashi J. Periodic contractions of the canine gall-bladder during the interdigestive state. $A m ~ J$ Physiol 1981; 240: G 183-9.

4 Peeters TL, Vantrappen G, Janssens J. Bile acid output and the interdigestive migrating motor complex in normals and in cholecystectomy patients. Gastroenterology 1980; 79: 678-81.

5 Wingate D, Ruppin H, Green WER et al. Motilininduced electrical activity in the canine gastrointestinal tract. Scand J Gastroenterol 1976; 11 (suppl 39): 111-8.

6 Thomas PA, Kelly KA, Go WLW. Does motilin regulate canine interdigestive gastric motility? Dig Dis Sci 1979; 24: 577-82.

7 Vantrappen G, Janssens J, Peeters TL, Bloom SR, Christofides ND, Hellemans J. Motilin and the interdigestive migrating motor complex in man. Dig Dis Sci 1979; 24: 497-500.

8 You CH, Chey WY, Lee KY. Studies on plasma 
motilin concentration and interdigestive motility of the duodenum in humans. Gastroenterology 1980; 79: 62-6.

9 Peeters TL, Vantrappen G, Janssens J. Fasting plasma motilin levels are related to the interdigestive motility complex. Gastroenterology 1980; 79: 716-9.

10 Bloom SR, Adrian TE, Michenere P, Sagor GR, Christofides ND. Motilin-induced gall-bladder contraction - a new mechanism. Gastroenterology 1981; 80: 1113.

11 Tjen H, Van der Pompe W, Cox P. Technetium 99 m-labelled diethyl-acetamilido-iminodiacetate: a new hepato-biliary agent. Br J Radiol 1977; 50: 735-9.

12 Christofides ND, Bryant MG, Ghatei MA et al.
Molecular forms of motilin in the mammalian and human gut and human plasma. Gastroenterology 1981; 80: 292-300.

13 Domschke W, Lux G, Mitznegg P, Neeb S, Strunz U, Domschke S. Release of motilin in man by exogenous and endogenous bile. Gastroenterology 1979; 76: 1123 .

14 Spellman SJ, Shaffer EA, Rosenthall L. Gallbladder emptying in response to cholecystokinin. A cholescintigraphic study. Gastroenterology 1979; 77: 115-20.

15 Krishnamurthy GT, Bobba VR, Kingston E. Radionuclide ejection fraction: a technique for quantitative analysis of motor function of the human gall-bladder. Gastroenterology 1981; 80: 482-90. 